\title{
Designing An Upper Body Resistance Training Program Using Closed Kinetic Chain Exercises
}

\author{
Britt Chandler
}

\section{ABSTRACT}

The purpose of this article is to summarize research on the effects of CKC and OKC upper body resistance training on serve velocity. Practical applications of this research are discussed and examples of how these exercises can be implemented into a tennis player's training program are provided.

\author{
Key words: bodyweight \\ training, serve velocity, \\ suspension training. \\ Received: 10 June 2020 \\ Accepted: 16 September 2020 \\ Corresponding author: Britt \\ Chandler, United States of \\ America. Email: \\ scjmanagingeditor@gmail.com
}

\section{INTRODUCTION}

Tennis players are always looking to increase the velocity of the ball coming off their racket. In particular, serve velocity is critical with higher ranked players exhibiting greater serve velocities than lower ranked players (Ulbricht, Fernandez-Fernandez et al. 2016). One of the primary methods used to increase ball velocity is through resistance training. Various training methods such as free weight resistance training (Kraemer, Hakkinen et al. 2003, Fernandez-Fernandez, Ellenbecker et al. 2013), plyometric training (Behringer, Neuerburg et al. 2013, Fernandez-Fernandez, Villarreal et al. 2016) and elastic band training (Treiber, Lott et al. 1998, Fernandez-Fernandez, Ellenbecker et al. 2013) have shown small to moderate increases in serve velocity. The majority of these studies have focused on open kinetic chain (OKC) upper body resistance training. OKC exercises have a fixed body position and a terminal segment which moves throughout the exercise such as a bench press, lat pull down, or knee extension. OKC exercises are dependent on an external load or machine to provide resistance. In contrast, closed kinetic chain (CKC) exercises have a fixed terminal segment and the body moves during the exercise such as a push-up, pull-up or squat. CKC exercises are usually weightbearing and use the exerciser's own body weight as resistance but may use an external load in addition to their bodyweight. Likely due to the ease of increasing load with OKC exercises, they are often preferred in upper body resistance training.

\section{COMPARISON OF CLOSED AND OPEN KINETIC CHAIN RESISTANCE} TRAINING

A recent study compared the effects of CKC and OKC upper body resistance training with equal loads on serve velocity in junior tennis players (Chandler 2019). The results of this study demonstrated that both methods of training produced improvements in serve velocity $(p<.05)$, with no significant difference between groups ( $p>05)$. However, the CKC group did produce larger increases in serve velocity. The CKC group increased average serve velocity $4.0 \mathrm{mph}$ while the OKC group increased $2.4 \mathrm{mph}$. Additionally, only the CKC training group produced improvements in upper body power $(p<.05)$ which was measured by a one arm medicine ball shot put. Both training groups produced similar improvements in upper body strength ( $p<.05)$. These results suggest that both OKC and CKC upper body resistance training can be used to increase serve velocity as well as upper body strength in tennis players. CKC upper body resistance training may also provide some performance benefits compared to OKC training as seen by the greater improvement in upper body power and larger increase in serve velocity.

The improvement in upper body power and the potential increase in serve velocity observed in this study with CKC training may be a result of improved muscular stability. The serve is a total body movement that requires force to be generated from the ground and up through the kinetic chain (Kovacs and Ellenbecker 2011). Along each link in the kinetic chain force must be created as well as transferred from the previous links in the chain. For this reason, muscles must be both producers of force as well as stabilizers to produce an optimal serve. CKC upper body exercises appear to increase both core and shoulder stability (Calatayud, Borreani et al. 2014). Therefore, improved stability through CKC upper body training may lead to a reduced loss of force transferred throughout the kinetic chain and ultimately higher ball velocity.

\section{PRACTICAL APPLICATIONS}

There are several practical applications that coaches can take from this research. Since CKC upper body resistance training produced similar improvements in strength and serve velocity coaches can 
prescribe these exercises in the training programs of their players. These exercises can be used as alternatives to more traditional OKC exercises to increase variety and provide a new training stimulus. For example, bench press variations can be replaced with a variety of push-up variations and dumbbell or cable machine rows can be replaced by a bodyweight inverted row. Table 1 provides a list of OKC upper body exercises and biomechanically similar CKC exercises that can be substituted in place of the OKC exercise. OKC exercises can still be performed but CKC exercises can be cycled into the pool of exercises that can be performed. Additionally, when creating an annual training plan coaches may want to place a greater emphasis on CKC upper body exercises during phases of training when power is a goal because of the improvement in power seen with these exercises. An upper body workout with a focus on CKC exercises is provided in Table 2 .

Table 1. List of open kinetic chain exercises and their biomechanically comparable closed kinetic chain exercises.

\begin{tabular}{|l|l|}
\hline Open Kinetic Chain Exercise & Closed Kinetic Chain Exercise \\
\hline Bench Press & Push-up \\
\hline Dumbbell Row & Inverted Row \\
\hline Overhead Press & Pike Push-up \\
\hline Lat Pull Down & Pull-up \\
\hline $\begin{array}{l}\text { Band Shoulder External } \\
\text { Rotation }\end{array}$ & $\begin{array}{l}\text { Suspension Trainer Shoulder } \\
\text { External Rotation }\end{array}$ \\
\hline Band Y's and T's & Suspension Trainer Y's and T's \\
\hline
\end{tabular}

Table 2. Upper body workout with an emphasis on CKC training.

\begin{tabular}{|l|l|}
\hline Exercise & Sets $\mathbf{x}$ Reps \\
\hline Dumbbell Push Press & $3 \times 5$ each arm \\
\hline Pull-Ups & $3 \times 5$ \\
\hline Weighted Push-Up & $3 \times 10$ \\
\hline Inverted Row & $3 \times 10$ \\
\hline Plank w/ Shoulder Taps & $3 \times 12$ \\
\hline Push-up Crawl & $3 \times 12$ \\
\hline
\end{tabular}

This information can also be useful for designing training programs when athletes are travelling. Tennis players spend a lot of time on the road at tournaments, especially at the higher levels of the sport. When players are away from home access to gyms and resistance training equipment may be limited. As a result, CKC upper body training may offer a practical advantage. A variety of CKC exercises require no external load and can be performed with only body weight and a suspension trainer. A suspension trainer is a common form of CKC upper body training that allows the athlete to easily increase or decrease the load (amount of bodyweight being lifted) by changing the position of their feet. Moving the feet closer to the anchor point increases the load and moving the feet farther away from the anchor point decreases the load. Coaches can prescribe CKC exercises during travel periods when facilities and equipment are not available knowing that their athletes can still improve strength and performance. Table 3 presents a sample CKC upper body workout using a suspension trainer that can be performed in the athlete's hotel room.

Table 3. Sample upper body CKC suspension trainer workout.

\begin{tabular}{|l|l|}
\hline Exercise & Sets x Reps \\
\hline Suspension Trainer Push-up & $3 \times 10$ \\
\hline Suspension Trainer Row & $3 \times 10$ \\
\hline $\begin{array}{l}\text { Suspension Trainer Shoulder External } \\
\text { Rotation }\end{array}$ & $3 \times 12$ \\
\hline Suspension Trainer Y's and T's & $3 \times 12$ \\
\hline
\end{tabular}

\section{CONCLUSION}

In conclusion, CKC upper body resistance training can be used as an effective method of improving strength and tennis performance. Strength and conditioning professionals can prescribe CKC upper body exercises in place of or in combination with traditional OKC exercises.

\section{ACKNOWLEDGEMENTS}

This study was supported in part by a grant from the International Tennis Federation.

\section{REFERENCES}

Behringer, M., S. Neuerburg, M. Matthews and J. Mester (2013). "Effects of Two Different Resistance-Training Programs on Mean Tennis-Serve Velocity in Adolescents." Pediatric Exercise Science 25(3): 370-384, https://doi.org/10.1123/pes.25.3.370

Calatayud, J., S. Borreani, J. C. Colado, F. Martin and M. Rogers (2014). "Muscle Activity Levels in Upper-Body Push Exercises with Different Loads and Stability Conditions." The Physician and Sports Medicine 42(4): 106-119, https://doi.org/10.3810/psm.2014.11.2097

Chandler, W. B. (2019). The Effects of Closed Kinetic Chain versus Open Kinetic Chain Upper Body Resistance Training on Serve Velocity in Junior Tennis Players, Rocky Mountain University of Health Professions, Provo, UT.

Fernandez-Fernandez, J., T. Ellenbecker, D. Sanz-Rivas, A. Ulbricht and 
A. Ferrautia (2013). "Effects of a 6-week Junior Tennis Conditioning Program on Service Velocity." Journal of Sports Science \& Medicine 12(2): 232-239.

Fernandez-Fernandez, J., E. S. D. Villarreal, D. Sanz-Rivas and M. Moya (2016). "The Effects of 8-Week Plyometric Training on Physical Performance in Young Tennis Players." Pediatric Exercise Science 28(1): 77-86, https://doi.org/10.1123/pes.2015-0019

Kovacs, M. and T. Ellenbecker (2011). "An 8-Stage Model for Evaluating the Tennis Serve: Implications for Performance Enhancement and Injury Prevention." Sports Health 3(6): 504-513, https://doi.org/10.1177/1941738111414175

Kraemer, W. J., K. Hakkinen, N. T. Triplett-Mcbride, A. C. Fry, L. P. Koziris, N. A. Ratamess, J. E. Bauer, J. S. Volek, T. McConnell, R. U. Newton, S. E. Gordon, D. Cummings, J. Hauth, F. Pullo, J. M. Lynch, S. J. Fleck, S. A. Mazzetti and H. G. Knuttgen (2003). "Physiological Changes with Periodized Resistance Training in Women Tennis Players." Medicine and Science in Sports and Exercise 35(1): 157-168, https://doi.org/10.1097/00005768-200301000-00024

Treiber, F. A., J. Lott, J. Duncan, G. Slavens and H. Davis (1998). "Effects of Theraband and lightweight dumbbell training on shoulder rotation torque and serve performance in college tennis players." The American Journal of Sports Medicine 26(4): 510-515, https://doi.org/10.1177/03635465980260040601

Ulbricht, A., J. Fernandez-Fernandez, A. Mendez-Villanueva and A. Ferrauti (2016). "Impact of Fitness Characteristics on Tennis Performance in Elite Junior Tennis Players." The Journal of Strength \& Conditioning Research 30(4): 989-998, https://doi.org/10.1519/JSC.0000000000001267

RECOMMENDED ITF TENNIS ACADEMY CONTENT (CLICK BELOW)

\section{ITF Academy}

Copyright (c) 2020 Britt Chandler

(c) (1)

This text is under a Creative Commons BY 4.0 license

You are free to Share - copy and redistribute the material in any medium or format - and Adapt the content - remix, transform, and build upon the material for any purpose, even commercially under the following terms:

Attribution: You must give appropriate credit, provide a link to the license, and indicate if changes were made. You may do so in

any reasonable manner, but not in any way that suggests the licensor endorses you or your use.

CCBY4.0 license terms summary CCBY4.0license terms 